Pharmacogn. Res.

\title{
Bioactivity of Diterpens from the Ethyl Acetate Extract of Kingiodendron pinnatum Rox. Hams
}

\author{
Komal Kumar Javarappa, Attemode Girijanna Devi Prasad', Mahadesh Prasad AJ², Chetana Mane ${ }^{3}$ \\ Department of Clinical and Experimental Medicine, Experimental Haematology Unit, University of Linkoping, Linkoping, Sweden, 'Department of Environmental \\ Science and ${ }^{2}$ Department of Biochemistry, PBM Mahajana PG Centre, Mysore, ${ }^{3}$ Department of Biochemistry, University of Mysore, Karnataka, India
}

\begin{abstract}
Background: Kingiodendron pinnatum Rox. Hams. is an endangered medicinal plant used in gonorrhoe, catarrhal conditions of genito-urinary and respiratory tracts. The scientific and pharmacological formulation of $K$. pinnatum has not been established so far though it is being traditionally used by tribes of the region. Objective: $\mathrm{P}$ hytochemical screening and identification of the bioactive compounds from the ethyl acetate extract of Kingiodendron pinnatum Rox. Hams. Materials and Methods: Chromatographic separation was carried out by thin layer chromatography and column chromatography. Bio-autography of the column fractioned extract and TLC chromatogram were evaluated in vitro for antibacterial activity. The PTLC, HP TLC were used for crude extract and HPLC, LCMS, FTIR, ${ }^{1} \mathrm{HNMR}$ and ${ }^{13} \mathrm{CNMR}$ were employed for the isolated compound in the ethyl acetate extract of $K$. pinnatum. Results: Evaluation of solvent system for chromatographic separation revealed that ethyl acetate: petroleum ether in the ratio of $7: 2.5 \mathrm{ml}$ was the most appropriate one for the separation of diterpene compounds. The antibacterial bio-autography screening of TLC separated compound showed positive activity with Staphylococcus aureus and negative activity with Escherichia coli. Spectroscopic analysis of the isolated compound from the ethyl acetate extract of $K$. pinnatum revealed the presence of diterpene compound. Conclusion: It is evident from the present study that the ethyl acetate extract of $K$. pinnatum is rich in diterpene compounds and having potential antibacterial activity.

Key words: Bio-autography, HPLC, HPTLC, LC-MS, NMR

SUMMARY

- Novel extraction method for phytochemicls from Kingidendron pinnatum at RT

- Antibacterial property of diterpens extracted from Kingiodendron pinnatum Rox. Hams aganist $S$. aureus
\end{abstract}

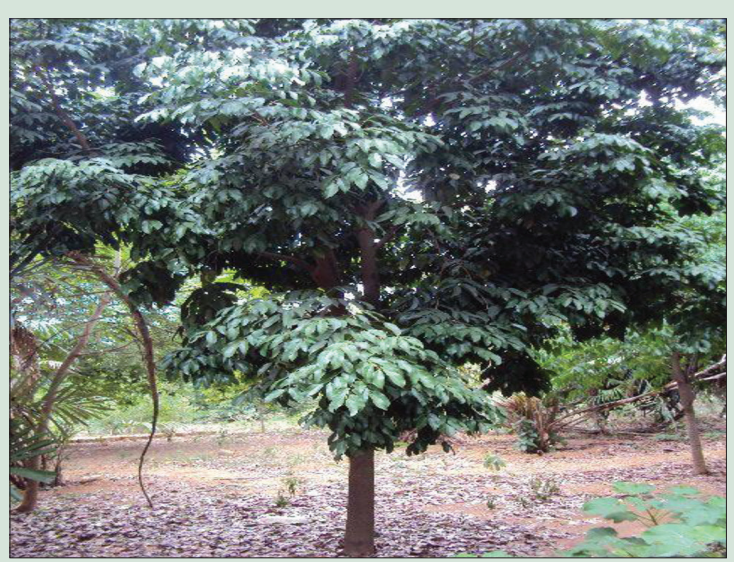

Abbreviations Used: TLC: Thin Layer Chromatography, PTLC: Preparatory Thin Layer Chromatography, HPTLC: High perormence Thin Layer chromatography, HPLC: High Performance Liquid Chromatography, LC-MS: Liquid chromatography Mass Spectra, FTIR: Fourier Transform Infrared Chromatography, NMR: Nuclear Magnetic Resonance

\section{Correspondence:}

Dr. Komal Kumar Javarappa,

Department of Clinical and Experimental

Medicine, Experimental Haematology Unit, University of Linkoping, Linkoping, Sweden. E-mail: kompaddy@yahoo.com DOI: $10.4103 / 0974-8490.188871$

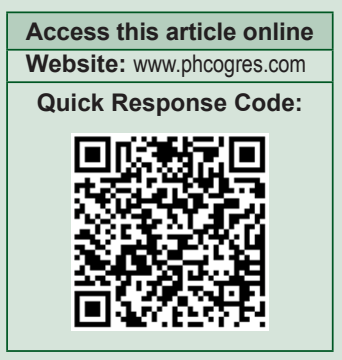

\section{INTRODUCTION}

Higher plants represent a rich source of bioactive compounds, with an almost infinite molecular diversity. These biomolecules often have specific functions, but many of them possess pharmacological properties which can be of use to humans. They also may provide lead compounds for the development of new drugs or they may act as indispensable tools in biomedical research. There is a potential need to test large numbers of plant extracts or compounds in a wide variety of biological assays. Since plants are synthesisers able to produce an unpredictable range of skeletal types and novel substances. It is prime importance to evaluate as many medicinal plants as possible in order to find sources of new drugs or lead compounds Kurt and Christian ${ }^{[1]}$ moreover, a crude extract of plant may contain several thousand different secondary metabolites and any phytochemical investigation of a given plant will reveal a spectrum of its constituents. The plant kingdom thus represents an enormous reservoir of pharmacologically valuable molecules to be discovered. ${ }^{[2,3]}$ Kingiodendron pinnatum is a threatened medicinal plant belonging to the family Fabaceae confined to the Western Ghats of India. The oleo-gum-resin of this plant species is used in gonorrhoea, catarrhal conditions of genito-urinary and respiratory tracts IUCN. ${ }^{[4]}$
The scientific and pharmacological formulation of $K$. pinnatum has not been established so far though it is being traditionally used by tribes of the region. Bioautographic assays are usually employed to screen antimicrobial activity by absorbingchemicals onto the surface of chromatographic plates and placing them directly in contact with a medium that is inoculated with bacterial or fungal cultures. These assays detect clear zones where microbial growth is inhibited. ${ }^{[5]}$ Isolation of biologically active constituents from the medicinal plant extracts remains a long and tedious process. The traditional methodology of

This is an open access article distributed under the terms of the Creative Commons Attribution-NonCommercial-ShareAlike 3.0 License, which allows others to remix, tweak, and build upon the work non-commercially, as long as the author is credited and the new creations are licensed under the identical terms.

For reprints contact: reprints@medknow.com

Cite this article as: Javarappa KK, Prasad AG, Mahadesh Prasad AJ, Mane C. Bioactivity of diterpens from the ethyl acetate extract of Kingiodendron pinnatum rox. hams. Phcog Res 2016;8:287-91. 
studying natural products includes the fractionation of a complex mixture, separation and isolation of the individual components using chromatographic techniques and structure elucidation using various spectroscopic methods. ${ }^{[6,7]}$

In the present study, attempt has been made to standardize the suitable solvent system for the separation of diterpens and antibacterial activity from the ethyl acetate extract of K. pinnatum.

\section{MATERIALS AND METHODS}

\section{Collection of the plant material}

Evergreen forest of the Western Ghats region of Hassan district, Karnataka, India was explored to locate the population of K ingiodendron pinnatum. The leaves of this plant were carefully exercised from this plant, shade dried and placed in polythene bags. Herbarium of this plant is deposited in the Biodiversity laboratory, Department of Environmental Science, University of Mysore.

\section{Preparation of crude ethyl acetate extract}

The leaves were shade dried at room temperature in a clean environment to avoid contamination for 14 days and powdered in a domestic grinder. Extract of this plant was made by maceration method using ethyl acetate as a solvent. Two hundred grams of shad dried leaf powder was extracted with ethyl acetate for $72 \mathrm{hrs}$ at room temperature. The extractc was first filtered through cheese cloth then through Whatman filter paper No. 1. First the filtrate was evaporated to $50 \mathrm{ml}$ at room temperature and then in a vacuum concentrator. The dried powder was stored in sterile glass bottle and used for different bioassays.

\section{Anti-bacterial activity of Kingiodendron pinnatum by agar well diffusion method}

The efficacy of the leaf extract was tested against bacteria, namely Bacillus subtilis MTCC 121, Escherichia coli MTCC 7410, Shigella flexnerri MTCC 731, Staphylococcus aureus MTCC 7443 and Xanthomonas campestris MTCC7908 by the agar-well diffusion method. ${ }^{[8]}$ The bacterial cultures were obtained from IMTECH-MT Chandigarh, India. In this method, $24 \mathrm{~h}$-old nutrient broth cultures of the test bacteria were swabbed uniformly on solidified sterile nutrient agar plates using a sterile cotton swab. Well of $6 \mathrm{~mm}$ diameter were bored aseptically in the inoculated plates with the help of a gel puncher and the extracts $(2.5,5.0$ and $10.0 \mathrm{mg} / \mathrm{ml}$ of $10 \% \mathrm{DMSO}$ ), standard (Gentamicin, $\mathrm{mg} / \mathrm{ml}$ ) and control (10\% DMSO) were added separately into the respectively labelled wells. The plates were incubated at $37^{\circ} \mathrm{C}$ for $24 \mathrm{~h}$ in an upright position and the zone of inhibition formed around the well was recorded. The experiment was carried out in triplicates and mean values were recorded.

\section{Column chromatography and thin layer chromatography}

The crude ethyl acetate extract of the $K$. pinnatum leaves was reconstituted in ethyl acetate and spotted on analytical TLC (silica gel G600, $0.25 \mathrm{~mm}$ thickness, Merck). Different solvent systems with different ratios were tried as mobile phase to determine the eluent with optimum performance. After separation of the compounds the TLC plate was exposed to iodine fumes and UV light.

\section{Column separation}

Column separation of the ethyl acetate extracts of Kingiodendron pinnatum was carried out with a glass column of internal diameter $80 \mathrm{~mm}$ and length $100 \mathrm{~cm}$ (Raghu chemicals, Mysore, India). Sufficient quantity of a column grade silica gel (100-200 mesh size) was wet-packed in to the column using ethyl acetate.

\section{Petroleum ether solvent system}

$40 \mathrm{~g}$ amount of the crude extract was first dissolved in $20 \mathrm{ml}$ of ethyl acetate, and passed through the column and continuously eluted with the mobile phase (ethyl acetate/petroleum ether: 7:2.5 ml ratio).

\section{Bioautography}

A thin layer chromatography (TLC) bioautographic agar-overlay method ${ }^{[9]}$ was used to analyse most active components in the ethyl acetate crude extract of K. pinnatum (as antibacterial agent). About $10 \mu \mathrm{l}$ of ethyl acetate extract of $K$. pinnatum was applied on pre-coated aluminium silica gel Merk plates. The plates were developed with petroleum ether and ethyl acetate $(7: 2.5 \mathrm{~mL}$ v/v). TLC bio-autography was carried out against Escherichia coli and Staphylococcus aureus. The developed TLC plates were thinly overlaid with molten nutrient agar inoculated with an overnight culture of bacteria. The plates were incubated in a dark and humid chamber overnight at $37^{\circ} \mathrm{C}$. Subsequently, the bioautogram was sprayed with an aqueous solution of 2, 3, 5 triphenyl tetrazolium chloride and further incubated at $37^{\circ} \mathrm{C}$ for $4 \mathrm{~h}$. inhibited microbial growth and appeared as clear zones in a pink background. The $\mathrm{Rf}$ values of the spots showing inhibit ion were determined.

\section{High performance thin layer chromatography and preparatory thin layer chromatography}

Chromatographic separation of ethyl acetate extract of the leaves was conducted using HPTLC purchased from CAMAG, Switzerland. Plant extract was applied with $100 \mu \mathrm{l}$ syringe on pre coated silica gel 60F254 HP TLC plates $(10 \times 10 \mathrm{~cm})$ with band length of $8 \mathrm{~mm}$ and track separation of $12 \mathrm{~mm}$ using Linomat $\mathrm{V}$ applicating device. The chromatograph was developed in twin trough chamber using solvent system of ethyl acetate: petroleum ether 2.5:7 and UV Detectors Wavelength selection: $366 \mathrm{~nm}$. The peaks, graph and spectra obtained were given in. For preparative thin layer chromatography, slurry of $40 \mathrm{~g}$ of silica gel in $84 \mathrm{ml}$ of distilled water was applied to a hundred glass plates totally $(20.3 \mathrm{~cm}$ square), with a thinlayer spreader (Research Specialties Co.,) producing a gel layer of 250 micron thickness. The plates were allowed to stand for 10 minutes at room temperature for 1 hour at $105^{\circ} \mathrm{C}$ in hot air oven and then in a desiccator for 2 hours. Later ethyl acetate extract of leaves was spotted on the plates (10 $\mu$ l each spot). Development of the plates was carried out using petroleum ether and ethyl acetate in the ration of $2.5 \mathrm{ml}: 7 \mathrm{ml}$ by the ascending method. Formation of the bands was observed under the UV light.

\section{High performance liquid chromatography}

High Performance Liquid Chromatography (HP LC) analysis was performed using different gradients of mobile phase in different run times. Analysis of the crude extract and separated compound was performed using $515 \mathrm{HP}$ LC pumps and 2489 UV/VIS detectors of Waters company, USA, having reverse phase water guard Column: Symmetry C18 $(5 \mu \mathrm{m}, 4.6 \times 250 \mathrm{~mm})$ and Hamilton microliter syringe using an injection volume of $20 \mu \mathrm{l}$. The data analysis was done using Empower 2 software. Detection was made at $254 \mathrm{~nm}$ and $28^{\circ} \mathrm{C}$. The HPLC mobile phase consisted of methanol and water (97: $3 \mathrm{ml}$ ). The mobile was filtered and degassed prior to use. ${ }^{[10]}$

\section{Liquid chromatography-mass spectra of isolated compound}

Analyses of isolated diterpene from Kingiodendron pinnatum was performed with Agilent (Waldbronn, Germany) RR 1200 SL system (binary pump S L, diode array detector G1315C Starlight and automatic injector G1367C SL) connected to a micrOToF -Q mass spectrometer model from Bruker Daltonics (Bremen, Germany). Analyses were carried 
out using Zorbax Eclipse XDB-C18 columns (Agilent) with a size and granulation of $2.1 \times 100 \mathrm{~mm} 2$ and $1.8 \mu \mathrm{m}$, respectively. Chromatographic separation was performed at a $0.5 \mathrm{ml} / \mathrm{min}$ flow rate using mixtures of solvents: A B (99.5\% acetonitrile/0.5\% water v/v) with a 3:2 split of the column effluent, so $0.2 \mathrm{ml} / \mathrm{min}$ was delivered to the ESI ion source. The elution steps were as follows: $0-5$ min linear gradient from 10 to $30 \%$ of $\mathrm{B}, 5-12$ min isocratic at $30 \%$ of $\mathrm{B}, 12-13$ min linear gradient from $30-95 \%$ of $\mathrm{B}$, and $13-15$ min isocratic at $95 \%$ of $\mathrm{B}$. After returning back to the initial conditions, the equilibration was achieved after $4 \mathrm{~min}$. The micrOToF -Q mass spectrometer consisted of an ESI source operating at a voltage of $\pm 4.5 \mathrm{kV}$, nebulization with nitrogen at 1.2 bar, and dry gas flow of $8.0 \mathrm{l} / \mathrm{min}$ at a temperature of $220^{\circ} \mathrm{C}$. The instrument was operated using the program MIC ROTOF control ver. 2.3, and data were using analyzed using the Bruker data analysis ver. 4 package. ${ }^{[11]}$

\section{Fourier transforms infrared spectroscopy}

FTIR spectra were recorded with a FTIR 460 plus Jasco. The powdered leaf sample of fractioned and separated compound of K. pinnatum was mixed with dried potassium bromide and prepared as pellets, scanned at room temperature $\left(25 \pm 2^{\circ} \mathrm{C}\right)$ at $4000-400 \mathrm{~cm}^{-1}$ spectral range. To improve the signal to noise ratio for each spectrum, 100 interferograms with a spectral resolution of $\pm 4 \mathrm{~cm}^{-1}$ were averaged. ${ }^{[12]}$

\section{${ }^{1} \mathrm{H}$ and ${ }^{13} \mathrm{C}$ nuclear magnetic resonance}

${ }^{1} \mathrm{H}$ and ${ }^{13} \mathrm{C}$ NMR spectra and HMQC and RO ESY of isolated diterpene from ethyl acetate extract of $K$. pinnatum were recorded on broker DRX 600 and Bruker Avance 800 instruments (Bruker, Karlsruhe, Germany) using CDC 13 as solvent. Chemical shifts are reported in ppm.

\section{RESULTS}

Extraction of phytochemicals from the leaves of $K$. pinnatum was carried out in dark condition using maceration method. The crude extract did not inhibit the growth of Bacillus subtilis MTCC 121, Escherichia coli MTCC 7410, Shigella flexneri MTCC 731, Staphylococcus aureus MTCC 7443 and Xanthomonas campestris MTCC7908. This may, possibly due to the antagonistic effects of the compounds present in the crude extracts, however, when the leaves extract was subjected [Figure 1] to PTLC and Bio-autography, the separated components, when tested for anti-microbial activity, showed inhibition for Staphylococcus aureus. Among the fourteen bands observed in ethyl acetate extract [Figure 1] seven bands were found to be active against Staphylococcus aureus and band one showed a high significant activity and hence further study was concentrated on this band. The areas of inhibition (colored white/light yellow on a purple/pink background) of the compounds from K. pinnatum against staphylococcus aureus were found at varying $\mathrm{Rf}$ values (0.09 to 0.9$)$. With band one shows significant activity against Staphylococcus aureus [Figure 2]. Investigations were carried out on this band. The band was re- extracted and further analyzed using HPTLC, HP LC, FTIR, LCMS, 1DNMR to assess the composition and functional groups present in this. HPTLC analysis showed different Rf values of the separated compounds and HPLC of the isolated compound showed a single peak with [Figure 3] retention time 50. The F TIR analysis indicated that significant peaks were found at: 1659 $\mathrm{cm}^{-1}$ is attributed to aldehyde, $1710 \mathrm{~cm}^{-1}$ is a carboxylic acid function and $1682 \mathrm{~cm}^{-1}$ attributed to a ketone. The presence of diterpene compound was further proven with the absorption band of hydroxyl (3500 - 3480 $\left.\mathrm{cm}^{-1}\right)$, ester carbonyl $\left(1270-1150 \mathrm{~cm}^{-1}\right)$ and phenyl [Figure 4]. (1600, $1420 \mathrm{~cm}^{-1}$ ). LCMS studies of the isolated compound was carried out, ESI was used with negative mode. Major fragment peaks was found at $\mathrm{m} / \mathrm{z}$ $79.03,156.78,204.94,494.20$. Here 332.10 is a parent ion and 528.22 is a daughter. The daughter ion is very stable showing maximum peak. M/Z $332\left(\mathrm{M}^{+}\right)$, and 204 are attributed to $(\mathrm{C} 14 \mathrm{H} 20 \mathrm{O})$ and the molecular weight of the compound is 332.10 [Figure 5]. Proton NMR of isolated compound having two vinyl protons (- $\mathrm{CH}=\mathrm{CH}-$ ), attached to $\mathrm{CH}_{2}$ groups and methyl

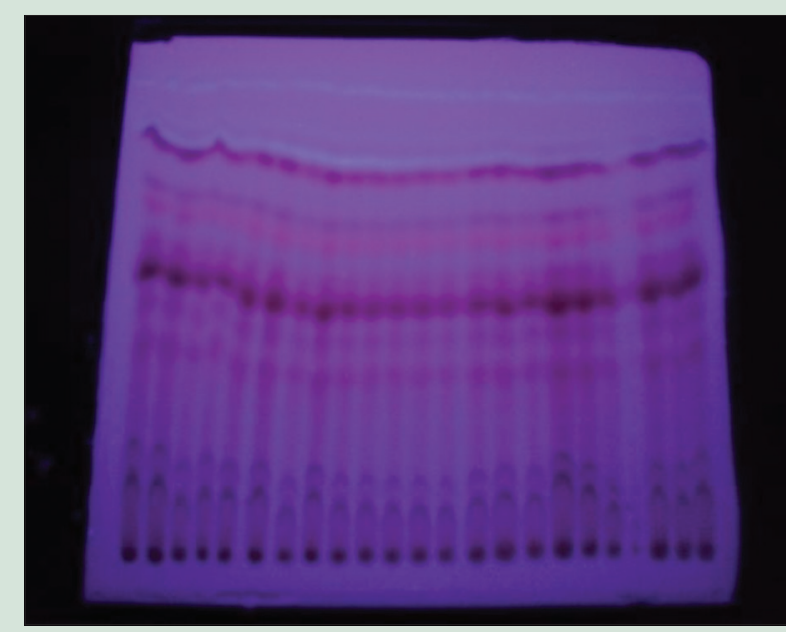

Figure 1: PTLC separation of phytochemicals from K.pinnatum

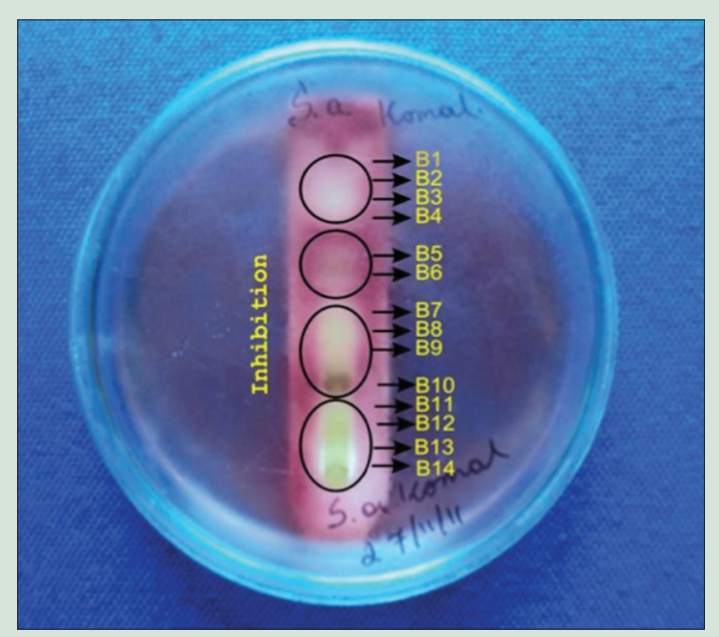

Figure 2: Bioutographic study of Kingiodendron pinnatum

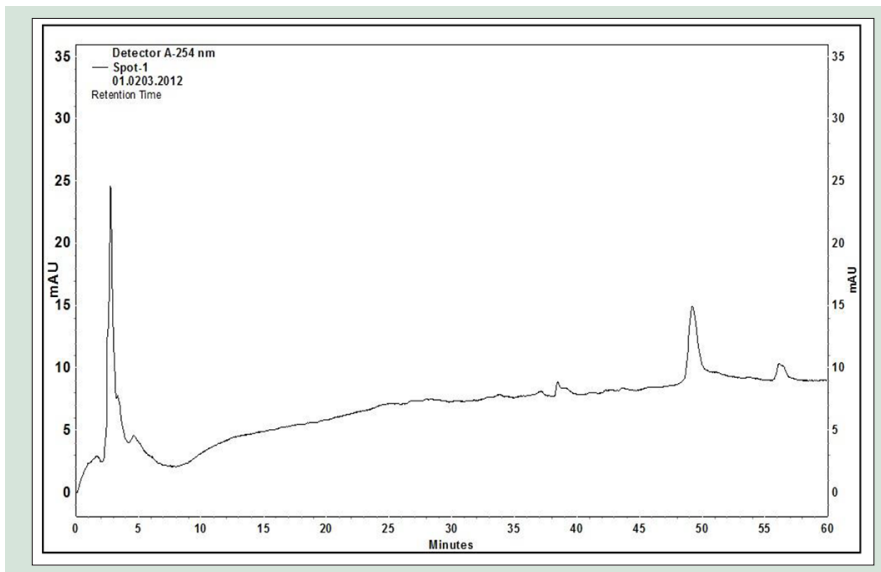

Figure 3: HPLC of Dipterpene isolated form K.pinnatum

groups and methylene groups. Also it is having oxygenated methylene group (-CH2-O-). In the carbon NMR we have 20 carbons: 2 quaternary, three methines, one oxygenated methylene, about 11 methylenes, and [Figures 6-9] three methyls. This compound could be a diterpene containing three methyl groups, one oxygenated methylene group, two vinylic protons, and two quaternary carbons, one of them could be $\mathrm{CO}$ or $\mathrm{CO}-\mathrm{NH}$. 
KOMAL JAVARAPPA, et al.: Antibacterial Property of Diterpens Aganist S. aureus

\section{DISCUSSION}

Plants produce a diverse range of biologically active molecules making them rich source of different types of medicines. Various techniques are employed for their investigation which includes bio-logical assays for phytochemical screening and their evaluation for presence of bioactivity. Isolation of pure bio-active constituents from plants remains a long tedious process. This procedure enables recognition of known metabolites in extracts in the earliest stages of separation and thus economically very important. To characterize the bioactive compounds several techniques were used among which chromatographic techniques were extensively used. ${ }^{[13]}$ Success in isolating compounds, which correspond to bands from the plant material, was largely dependent on the type of solvent combination used in the extraction process. This implies that solvent with intermediary polarity separates more active components. ${ }^{[14]}$ TLC is the simplest method for separating plants constituents because the method is easy to run and reproducible and requires little time. However, for efficient separation and identification of metabolites, good selectivity and sensitivity of detection, together with capability of providing structural information by hyphenated techniques such as HPLC, HP TLC, LC-MS, FTIR, 1DNMR such as ${ }^{13} \mathrm{CNMR}$ and ${ }^{1} \mathrm{HNMR}$ techniques. Bio-autography agar overlay method is considered as one of the most efficient methods for the detection of antimicrobial compounds. ${ }^{[6]}$ The main focus of the present study was to investigate the suitable solvent system for the separation and to find out active components from the ethyl acetate extract of $K$. pinnatum using chromatographic and Bio-autographic technique. An interesting finding from the present study is that the crude extract did not showed the anti-bacterial activity but in the Bio-autographic

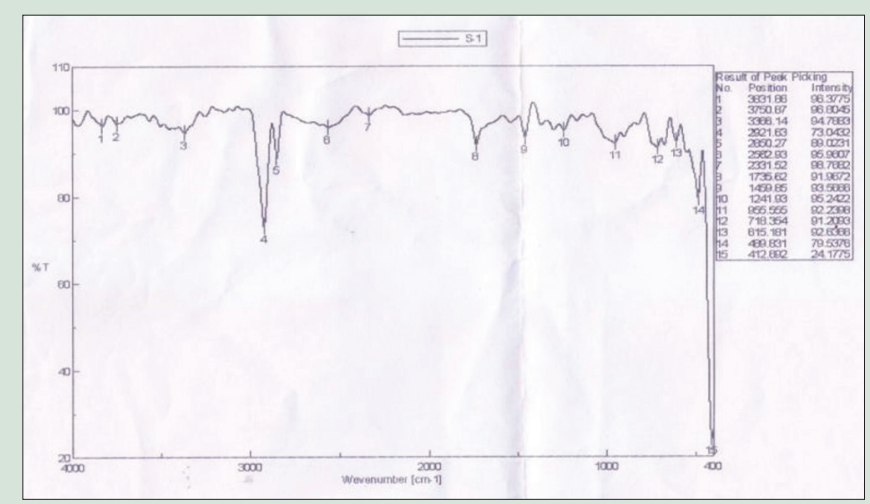

Figure 4: FTIR spectra of diterpene isolated from Kingiodendran Pinnatum

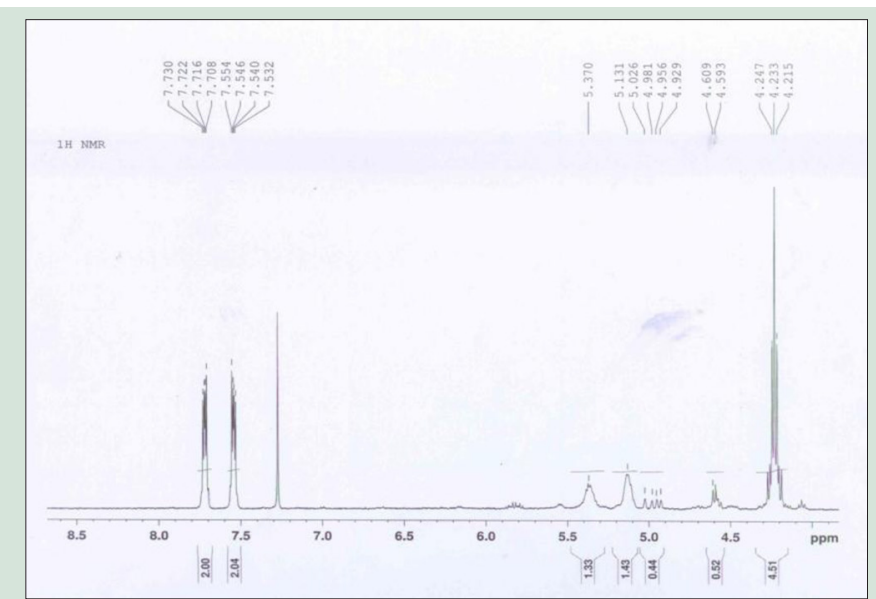

Figure 6: ${ }^{1} \mathrm{HNMR}$ Spectra of Diterpene isolated from the ethyl acetate extract of Kingiodendron pinnatum method, the separated compounds from the same extract by thin layer chromatography (TLC) showed the activity against staphylococcus aureus [Figure 3]. However, negative results do not indicate the absence of bioactive constituents, nor that the plant is inactive. Active compound (s) may be present in insufficient quantities in the crude extracts to show activity with the dose levels employed. ${ }^{[15]}$ Lack of activity can thus only be proven by using large doses Farnsworth. ${ }^{[16]}$ Alternatively, if the active principle is present in high enough quantities, there could be other constituents exerting antagonistic effects or negating the positive effects of the bioactive agents. ${ }^{[17]}$ With no anti-bacterial activity, extracts may be active against other bacterial species which were not tested Shale et al. ${ }^{[18]}$

\section{CONCLUSION}

It is inferred that the ethyl acetate extract of $K$ ingiodendron pinnatum contained diterpens with antibacterial properties against $S$. aureus. The compounds were active at low concentration. These active compounds were successfully concentrated using a series of techniques, including solvent extraction, TLC, preparative TLC, column chromatography. This facilitated for the isolation of pure diterpene with activity against

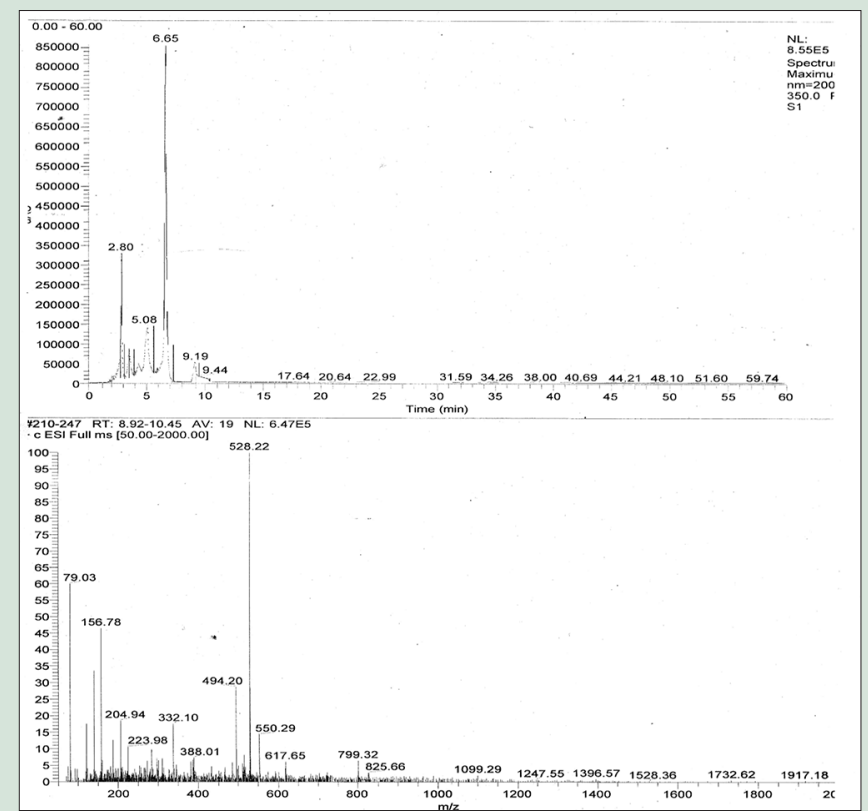

Figure 5: LC-MS specra of Diterpene isolated from Kingiodendron pinnatum

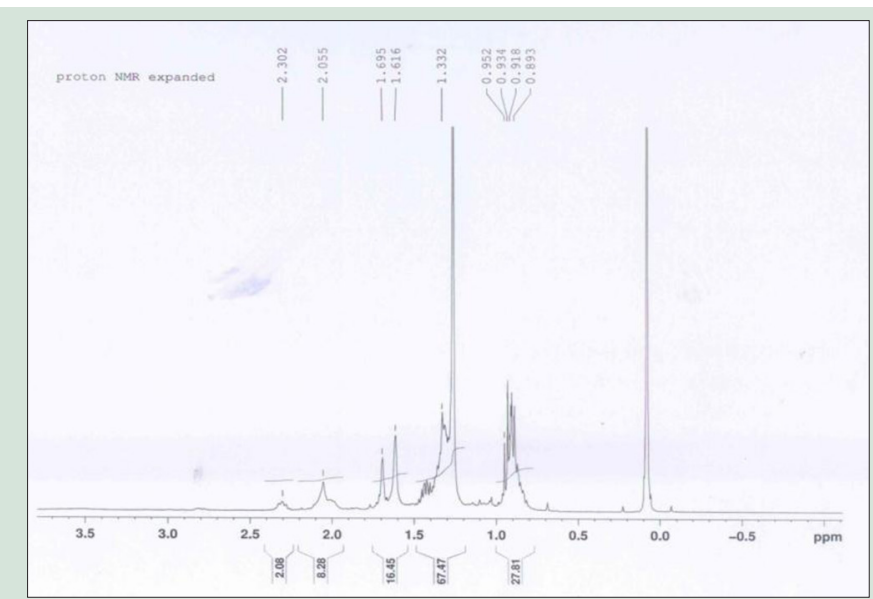

Figure 7: ${ }^{1} \mathrm{HNMR}$ (Expanded) spectra of diterpene isolated from the ethyl acetate extract of Kingiodendron pinnatum 


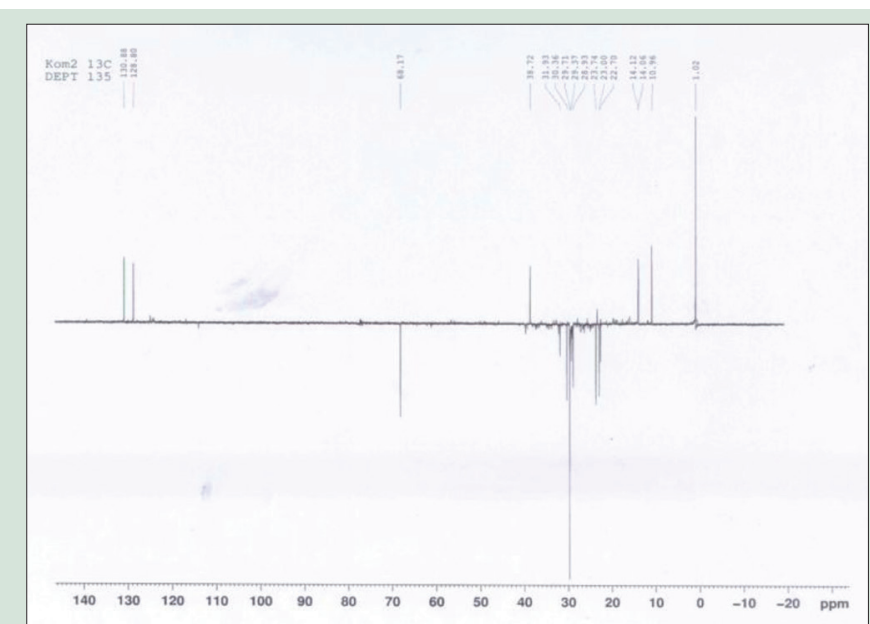

Figure 8: ${ }^{13} \mathrm{CNMR}$ spectra of Diterpene isolated from the ethyl acetate extract of Kingiodendron pinnatum (DEPT135)

S. aureus at relatively low concentration. The standardization of solvent system for the separation of bioactive compounds from the medicinal plant $K$. pinnatum is the first report which serves as a fingerprint for future research work. The basic information related to the chemical constituents of K.pinnatum which offers scope for further purification and identification of bioactive compounds. Bio-autography was found to be the most suitable method for assessing anti-bacterial activity in the crude extract of $K$. pinnatum. Our research investigation shows that extraction of phytochemicls at room temperature is a beneficial approach for purification of potent anti-microbial compounds from this plant. Purification of bio-active compounds is in process.

\section{Acknowledgment}

The authors are thankful to Institute of Excellence, University of Mysore, for the financial support of this project references no UOM. DV2/30/ PDF/PA.IOE.

\section{Financial support and sponsorship}

Institute of Excellence, University of Mysore.

\section{Conflicts of interest}

There are no conflicts of interest.

\section{REFERENCES}

1. Kurt H, Christian T. Search for new lead compounds from higher plants. Chimia 2000;54:652-7.

2. Potterat O, Hostettmann K. Encyclopedia of Environmental Biology. Vol. 3. London: Academic Press; 1995. p. 139.

3. Hamburger M, Marston A, Hostettmann K. Search for new drugs in plant origin in Advances in Drug Research. Vol. 20. London: B. Testa Editor. Academic Press; 1991. p. 167

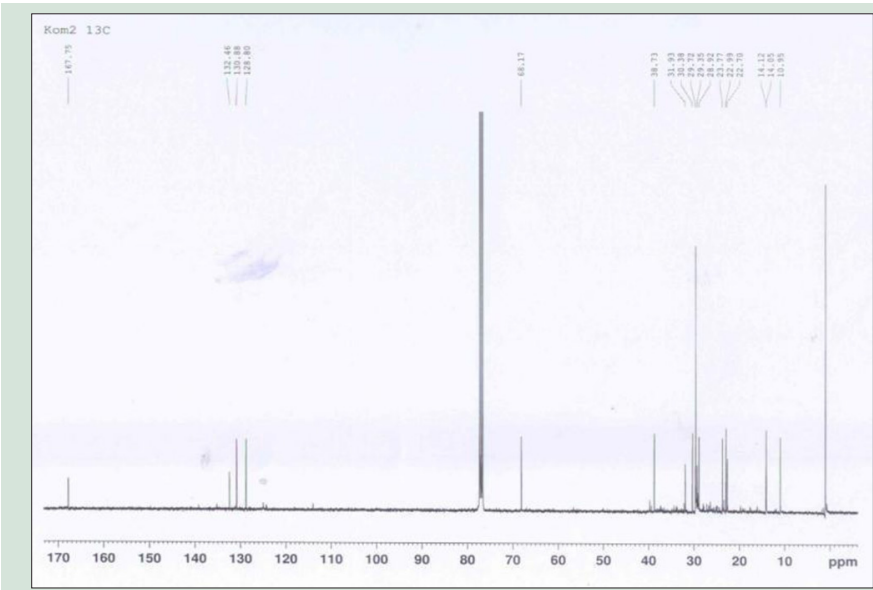

Figure 9: ${ }^{13} \mathrm{CNMR}$ spectra of Diterpenes isolated from the ethyl acetate extract of Kingiodendron pinnatum

4. CAMPWorkshops on Medicinal Plants, India 1998. Kingiodendron pinnatum. In: IUCN. IUCN Red List of Threatened Species. Version 2011; 2011. Available from: http://www.iucnredlist.org.

5. Homans AL, Fuchs A. Direct bioautography on thin-layer chromatograms as a method for detecting fungitoxic substances. J Chromatogr 1970;51:327-9.

6. Mueen Ahmed KK. Introduction to isolation, identification and estimation of lead compounds from natural products. In: Hiremath SR, editor. Textbook of Industrial Pharmacy. Chennai, India: Orient Longman Private Ltd.; 2008. p. 345-79.

7. Hota D. Evalution of plant extracts. In: Bioactive Medicinal Plants. New Delhi: Gene-Tech Books; 2010. p. 86-7.

8. Adeniyi B, Ayepola O. The phytochemical screening and antimicrobial activity of leaf extracts of Eucalyptus camaldulensis and Eucalyptus torrelliana (Myrtaceae). Res J Med Plant 2008;2:34-8.

9. Alagesaboopathi C. Anti-microbial potential and phytochemical screening of Andrographis affinis Nees - An endemic medicinal plant from India. Int J Pharm Pharm Sci 2011;3 Suppl 2:157-9

10. Ceyhun Sezgin E, Artik N. Determination of saponin content in Turkish tahini halvah by using HPLC. Adv J Food Sci Technol 2010;2:109-15.

11. Staszków A, Swarcewicz B, Banasiak J, Muth D, Jasinski M, Stobiecki M. LC/MS profiling of flavonoid glycoconjugates isolated from hairy roots, suspension root cell cultures and seedling roots of Medicago truncatula. Metabolomics 2011;7:604-13.

12. Cakmak G, Togan I, Severcan F. 17Beta-estradiol induced compositional, structural and functional changes in rainbow trout liver, revealed by FT-IR spectroscopy: A comparative study with nonylphenol. Aquat Toxicol 2006;77:53-63.

13. Patra J, Gouda S, Sahoo S, Thatoi H. Chromatography separation, H NMR analysis and bioautography screening of methanol extract of Excoecaria agallocha L. from Bhitarkanika, Orissa, India. Asian Pac J Trop Biomed 2012;2:S50-6.

14. Masoko P, Picard J, Eloff N. The antifungal activity of twenty-four Southern African Combretum species (Combretaceae). S Afr J Bot 2007;73:173-83.

15. Taylor S, Rabe T, McGraw J, Jager A, Van Staden J. Towards the scientific validation of traditional medicinal plants. Plant Growth Regul 2001;34:23-37.

16. Farnsworth R. Biological approaches to the screening and evaluation of natural products. In: Rasoanaivo P, Ratsimamanga-Urverg S, editors. Biological Evaluation of Plants with Reference to the Malagasy Flora. Madagascar: NAPREAC; 1993. p. 35-43.

17. Jager $K$, Hutchings $A$, van Staden J. Screening of Zulu medicinal plants for prostaglandin-synthesis inhibitors. J Ethnopharmacol 1996;52:95-100.

18. Shale L, Strik A, Van Staden J. Screening of plants used by Southern African traditional healers in the treatment of dysmenorrhoea for prostaglandin-synthesis inhibitors and uterine relaxing activity. J Ethnopharmacol 1999;64:9-14.

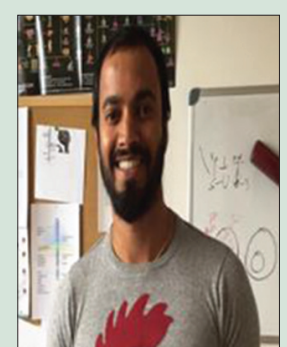

Komal Kumar Javarappa

\section{ABOUT AUTHOR}

Komal Kumar Javarappa, currently holds position of Research scientist in Leukemia research at University of Helsinki, Finland, He has completed his first postdoctoral training in the field of Leukemia at the University of Linkoping, Sweden. He received his $\mathrm{PhD}$ degree in Environmental Science, University of Mysore and he is a Editorial board member and a reviewer of several international scientific journals. 